\title{
An overview of cross-cultural music corpus studies
}

\author{
Patrick E. Savage \\ Keio University Shonan Fujisawa Campus, Faculty of Environment and Information Studies
}

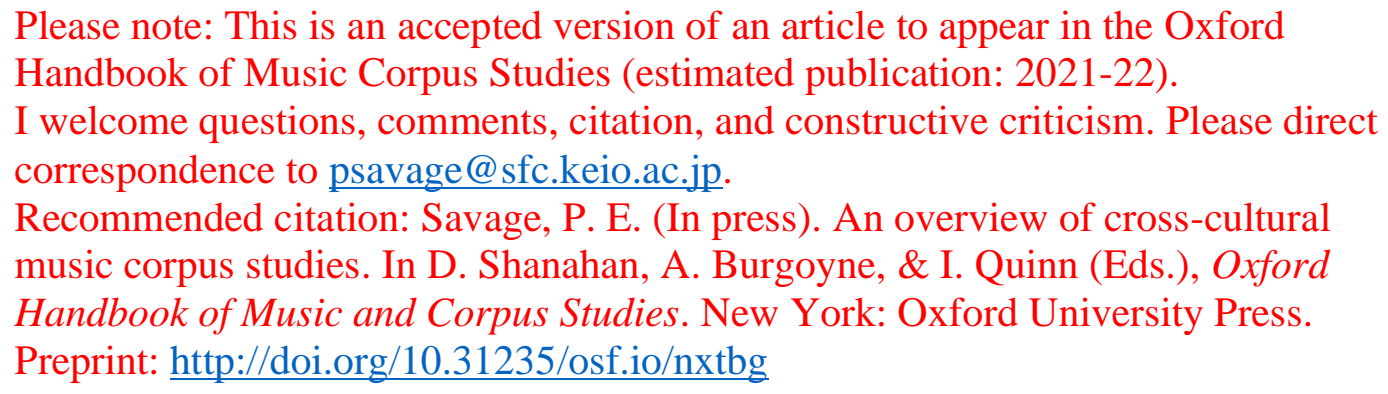

\begin{abstract}
:
The past few decades have seen a rapid increase in the availability and use of large music corpora. However, most music corpus studies remain limited to Western music, limiting our ability to understand the diversity and unity of human music throughout the world. I argue for the potential of cross-cultural corpus studies to contribute to comparative musicological studies in domains including music classification, evolution, universals, and human history. I highlight and discuss a number of important crosscultural corpora, including the Berlin Phonogramm-Archiv, CompMusic Project, Essen Folksong Collection, Cantometrics Project, Garland Encyclopedia of World Music, Natural History of Song, and Deep History of Music projects. In the process, I discuss the pros and cons of music notation vs. recordings, automatic vs. manual analysis, regional vs. global analysis, and associated challenges regarding choosing appropriate analysis methods that can allow meaningful comparison across cultures. I argue for the need for bigger and better global music corpora and more emphasis on integration within and beyond academia, including to domains such as the music industry and cultural heritage organizations.
\end{abstract}

\section{Introduction: The weirdest music in the world?}

The invention of computers has transformed musicology, just as it has transformed society at large. Where once scholars had to manually analyze and compare musical examples one by one, computers can now automatically process large corpora containing hundreds, thousands, or even millions of musical examples. Computers have been a driving force in the blossoming of music corpus studies leading to this volume and to the creation of the new field of Music Information Retrieval (MIR). Yet the conclusions that can be generated from such analyses are ultimately limited by the nature of the corpora that are inputted as data.

Despite great efforts by ethnomusicologists to collect diverse music styles from around the world, music corpus studies today remain dominated by the study of Western music, limiting their ability to generalize to answer broader questions about human music or to answer more specific questions about the role of music in different cultures. For example, in the twovolume special issues of Music Perception devoted to corpus methods (Temperley and VanHandel 2013; VanHandel and Temperley 2014), all of the corpora analyzed were drawn 
from either Western classical music (e.g., string quartets, Bach, Mozart), or Western popular music (e.g., jazz). A look at recent proceedings of the International Society for Music Information Retrieval conferences (https://ismir.net) reveals a similar emphasis on Western music with a few notable exceptions, particularly involving Xavier Serra's CompMusic project (Serra 2011, 2017; discussed further below). Vast corpora of Western popular music such as the "Million Song Dataset" (Bertin-Mahieux et al. 2011) are excellent resources for understanding Western popular music, but increasing the size of such datasets does not make them any more useful for generalizing about all human music. Although an emphasis on Western music is understandable given researchers' demographic backgrounds and the incentives for studying music with high historical prestige and economic value, it is not ideal (Jacoby et al. 2020).

In other fields, such as psychology, researchers have recently become more aware of the dangers of generalizing based on non-representative Western samples. An influential article, entitled "The weirdest people in the world?", criticized psychology's reliance on participants from Western, Educated, Industrial, Rich, and Democratic societies, labeled with the acronym "WEIRD" (Henrich, Heine, and Norenzayan 2010). This was not merely a rhetorical device - Henrich et al. provided substantial evidence that not only did findings from "WEIRD" societies not generalize to other societies, but WEIRD societies were frequent outliers compared to the rest of the world. They concluded that WEIRD societies "may represent the worst population on which to base our understanding of Homo sapiens" (Henrich, Heine, and Norenzayan 2010:82). Although we don't yet have conclusive evidence to know whether the analogy holds for WEIRD music, my intuition is that WEIRD music particularly Western classical music - may well represent one of the worst repertoires on which to base our understanding of human music. Among other things, the emphasis on instrumental music found in much Western classical music is unusual from a global perspective, where the vast majority of music is vocal (Savage, Brown, et al. 2015; Brown and Jordania 2013).

A crucial question that any study needs to address from the outset is: what is the scope and purpose of the study? If the purpose is to investigate specific details of a given musical genre or subgenre, then it is appropriate to limit one's corpus accordingly. As Temperley and VanHandel emphasize:

"standard statistical techniques can be used to determine whether a pattern observed in a sample of pieces can reliably be generalized to the larger population under investigation. It is important to decide exactly what that "larger population" is - the music of a single composer, a specific compositional school or style, or a broader musical idiom (e.g., "'common-practice Western music') — and to sample it appropriately." (Temperley and VanHandel 2013:2)

However, if the goal is to understand the nature of human music more broadly, then even the broadest example provided by Temperley and VanHandel, "common-practice Western music", is not nearly broad enough to provide the required generality. In this chapter I will review a variety of diverse musical corpora and discuss their potential for future investigations of human music (Table 1).

Table 1. Overview of case studies reviewed

\begin{tabular}{|l|l|l|l|l|}
\hline Corpus & Sample size & Sample scope & $\begin{array}{l}\text { Sample } \\
\text { type }\end{array}$ & Methodology \\
\hline Million Song & $1,000,000$ & Culture-specific & Audio & Automatic \\
\hline
\end{tabular}




\begin{tabular}{|c|c|c|c|c|}
\hline Dataset & songs & $\begin{array}{l}\text { (Western popular } \\
\text { music) }\end{array}$ & & \\
\hline Densmore & 2,083 songs & $\begin{array}{l}\text { Culture-specific } \\
\text { (Native } \\
\text { American) }\end{array}$ & Notation & Manual \\
\hline CompMusic & $\begin{array}{l}>10,000 \\
\text { recordings }\end{array}$ & $\begin{array}{l}\text { Regional ( } 5 \\
\text { Eurasian cultures) }\end{array}$ & $\begin{array}{l}\text { Audio + } \\
\text { notation }\end{array}$ & Automatic \\
\hline $\begin{array}{l}\text { Essen } \\
\text { Folksong } \\
\text { Database }\end{array}$ & 9,647 songs & $\begin{array}{l}\text { Regional } \\
\text { (European }+ \\
\text { Chinese) }\end{array}$ & Notation & Manual \\
\hline $\begin{array}{l}\text { Melodic } \\
\text { evolution }\end{array}$ & $\begin{array}{l}10,061 \\
\text { songs }\end{array}$ & $\begin{array}{l}\text { Regional (English } \\
+ \text { Japanese) }\end{array}$ & Notation & $\begin{array}{l}\text { Semi- } \\
\text { automatic }\end{array}$ \\
\hline $\begin{array}{l}\text { Berlin } \\
\text { Phonogramm- } \\
\text { Archiv }\end{array}$ & $\begin{array}{l}13,611 \text { wax } \\
\text { cylinders }+ \\
>100,000 \\
\text { other } \\
\text { recordings }\end{array}$ & Global & Audio & $\begin{array}{l}\text { Not yet } \\
\text { analyzed }\end{array}$ \\
\hline Cantometrics & 5,779 songs & Global & Audio & Manual \\
\hline $\begin{array}{l}\text { Garland } \\
\text { Encylopedia } \\
\text { of World } \\
\text { Music } \\
\end{array}$ & $\begin{array}{l}304 \\
\text { recordings }\end{array}$ & Global & Audio & $\begin{array}{l}\text { Manual / } \\
\text { automatic }\end{array}$ \\
\hline $\begin{array}{l}\text { Natural } \\
\text { History of } \\
\text { Song }\end{array}$ & $\begin{array}{l}118 \\
\text { recordings }+ \\
4,709 \text { text } \\
\text { descriptions }\end{array}$ & Global & $\begin{array}{l}\text { Audio + } \\
\text { notation }\end{array}$ & $\begin{array}{l}\text { Manual + } \\
\text { automatic }\end{array}$ \\
\hline $\begin{array}{l}\text { Deep History } \\
\text { of Music }\end{array}$ & $\begin{array}{l}>100,000 \\
\text { recordings } \\
(8,200 \\
\text { published })\end{array}$ & Global & Audio & Automatic \\
\hline
\end{tabular}

\section{Comparative musicology and corpus studies}

Cross-cultural musical corpora can be useful both for culture-specific analysis of the kind promoted by ethnomusicologists and some MIR scientists (e.g., Tzanetakis et al., 2007; Serra, 2017) or for cross-cultural comparative musicology as advocated by myself and others (e.g., Lomax, 1968; Savage and Brown 2013). In this chapter I will focus primarily on this latter application, without intending to diminish the value of the former. A broad understanding of the nature of human music is a major goal of comparative musicology, and cross-cultural music corpus studies are thus a key method by which to achieve this goal (Savage and Brown 2013). Although originally restricted to the comparative study of folk and/or non-Western musics, the definition has been expanded to include the comparative study of all music (Savage and Brown 2013).

Comparative musicology has its roots in the late $19^{\text {th }}$ century and early $20^{\text {th }}$ century work of Carl Stumpf (2012 [1911]), Erich von Hornbostel (1975), Carl Sachs (1962), and other members of the "Berlin school" of comparative musicology. The discipline of comparative musicology changed its name from "comparative musicology" to "ethnomusicology" 
following World War II and began to emphasize ethnographic "thick description" (Geertz 1973) of individual musical cultures rather than cross-cultural scientific comparison.

Although this shift involved a confluence of complex reasons, one key motivation for this change was a reaction against Eurocentric models of unilinear cultural evolution used by early comparative musicologists, particularly after seeing scientific racism used by Nazi Germany to justify its atrocities (see Nettl 2015; Nettl and Bohlman 1991; Toner 2007; Schneider 2008; Savage and Brown 2013; Savage 2019 for detailed discussion). However, Steven Brown and I have recently proposed a "new comparative musicology" (Savage and Brown 2013) in which we take advantage of new interdisciplinary theories and methods from fields such as cultural evolution and digital humanities to help return to the unanswered questions of comparative musicology. In particular, we emphasize using quantitative, crosscultural musical comparison to aid our understanding of five broad areas: 1) classification of music, 2) music and human history, 3) musical universals, 4) cultural evolution of music, and 5) biological evolution of music.

Early comparative musicologists were fascinated by the diversity of the world's music that was becoming known in the late $19^{\text {th }}$ century as European colonialism and the newly invented phonograph brought exotic recordings, instruments, and musicians to Europe from around the world. One of the major achievements of these early comparative musicologists was the creation of the first global music corpus: the Berlin Phonogramm-Archiv. Although the archive was fragmented for much of the $20^{\text {th }}$ century due to the events surrounding World War II and the Cold War, much of the original $\sim 13,000$ wax cylinders were preserved and eventually reunited and supplemented with over 100,000 tape recordings and other additional items (Ziegler 2006, 2017). A selection of 114 songs from wax cylinder recordings was published in digital form (Wiedmann, Kopal and Wegner 2014). Although the early wax cylinder technology produced low-quality recordings, they provide a unique window into traditional music around the world from over a century ago at a time before globalization had made a substantial impact on the music of many indigenous cultures.

Corpus studies are particularly important in comparative musicology because the globalization of Western music has been so pervasive that there is hardly anywhere in the world today where people have not been heavily exposed to it (Huron 2008). There are still some indigenous populations who do still display striking differences in music perception compared to populations accustomed to hearing Western music. For example, the Tsimané in the Amazon appear to be indifferent to musical dissonance (McDermott et al. 2016). Such populations are now extremely rare and difficult to engage with, but their traditional music is often preserved in historical recordings even if such music is no longer performed.

Although the early comparative musicologists were strongly interested in scientifically testing general theories about music using cross-cultural data, they did not yet have access to modern computers to allow for comparison on large scales. As a result, many of the early studies were based on fairly sparse data. Alexander Ellis's (1885) seminal article "On the musical scales of various nations", in which he developed the "cent" scale for precisely measuring musical intervals down to $1 / 100^{\text {th }}$ of a semitone, was one of the most comprehensive and broad-ranging of the time, but he still only applied his cent measurement technique to a few examples each from six Eurasian cultures (Greece, Arabia, India, Java, China, and Japan). This limited scope did not stop Ellis from making a sweeping - and still often-quoted - conclusion:

"The final conclusion is that the Musical Scale is not one, not 'natural,' nor even founded necessarily on the laws of the constitution of musical sound so beautifully 
worked out by Helmholtz, but very diverse, very artificial, and very capricious." (Ellis 1885:526)

\section{Computers in comparative musicology}

Later in the $20^{\text {th }}$ century, several scholars began taking advantage of the advent of computers to begin comparative musicological studies on a broader scale. Bertrand Bronson (1949, 1959-72, 1969) focused on symbolic musical notation, and developed a semi-automated technique for comparing melodic transcriptions that allowed him to compare over 4,000 melodic variants of the Child ballads and sort them into "tune families" (groups of related melodies, analogous to language families; Bayard 1950). Although Bronson's efforts were focused on the specific repertoire of British-American folksongs, his efforts were also aimed toward a broader cross-cultural understanding of melodic evolution. I have recently built on his methods by incorporating automated sequence alignment algorithms from molecular genetics (Savage and Atkinson 2015; Fig. 1), and applied these techniques successfully not only to Bronson's (1959-72) original corpus of 4,125 Child ballads, but also to a corpus of 5,937 melodic variants of traditional Japanese folk songs (NHK 1944-94) and a corpus of 40 melodies involved in copyright disputes (Savage et al., 2018). This analysis revealed several cross-cultural similarities in the mechanisms of melodic evolution despite major differences in the specific tonal systems used (Savage 2017; Savage et al. 2020).

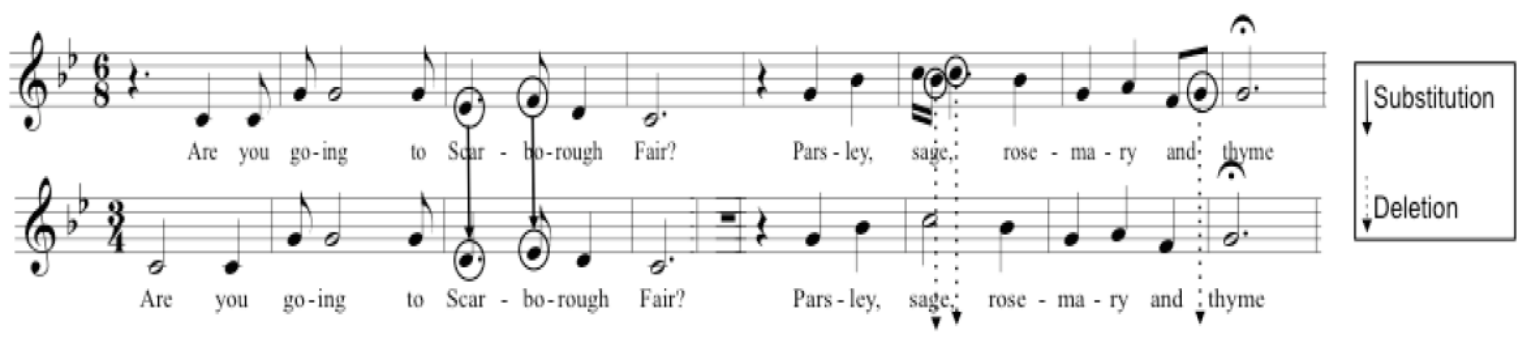

Figure 1. An example of folk song analysis via melodic sequence alignment (Savage 2019)

More ambitiously still, Alan Lomax attempted to apply new computer power not to symbolic music notation but to audio recordings from across the globe (Savage 2018). By this point, several generations of musicologists since the founding of the Berlin Phonogram and technological improvements such as the advent of LP recordings had resulted in a much larger and higher quality sample of recordings from around the world. Furthermore, these recordings were now being performed by people who were actually spending substantial amounts of time living in and working with the communities they were recording, resulting in much more knowledge and data not only about the musical sound but also about the cultural context in which that music was being created. Lomax created a massive global corpus of thousands of song recordings from hundreds of cultures around the world and, together with Victor Grauer, invented a new method called "Cantometrics" ("canto" = song, "metrics" = measure) by which to compare these recordings. Cantometrics eventually settled on 36/37 different musical dimensions including aspects of melody, rhythm, form, and - especially performance style (e.g., vocal timbre, group coordination; see Fig. 2). Lomax then worked with anthropologists such as Conrad Arensberg to integrate his Cantometric data with social structure data from George Murdock's (1967) Ethnographic Atlas and run statistical correlations to test his hypothesis that a culture's song style was functionally connected to its social structure (Lomax 1968, 1976, 1980, 1989). 


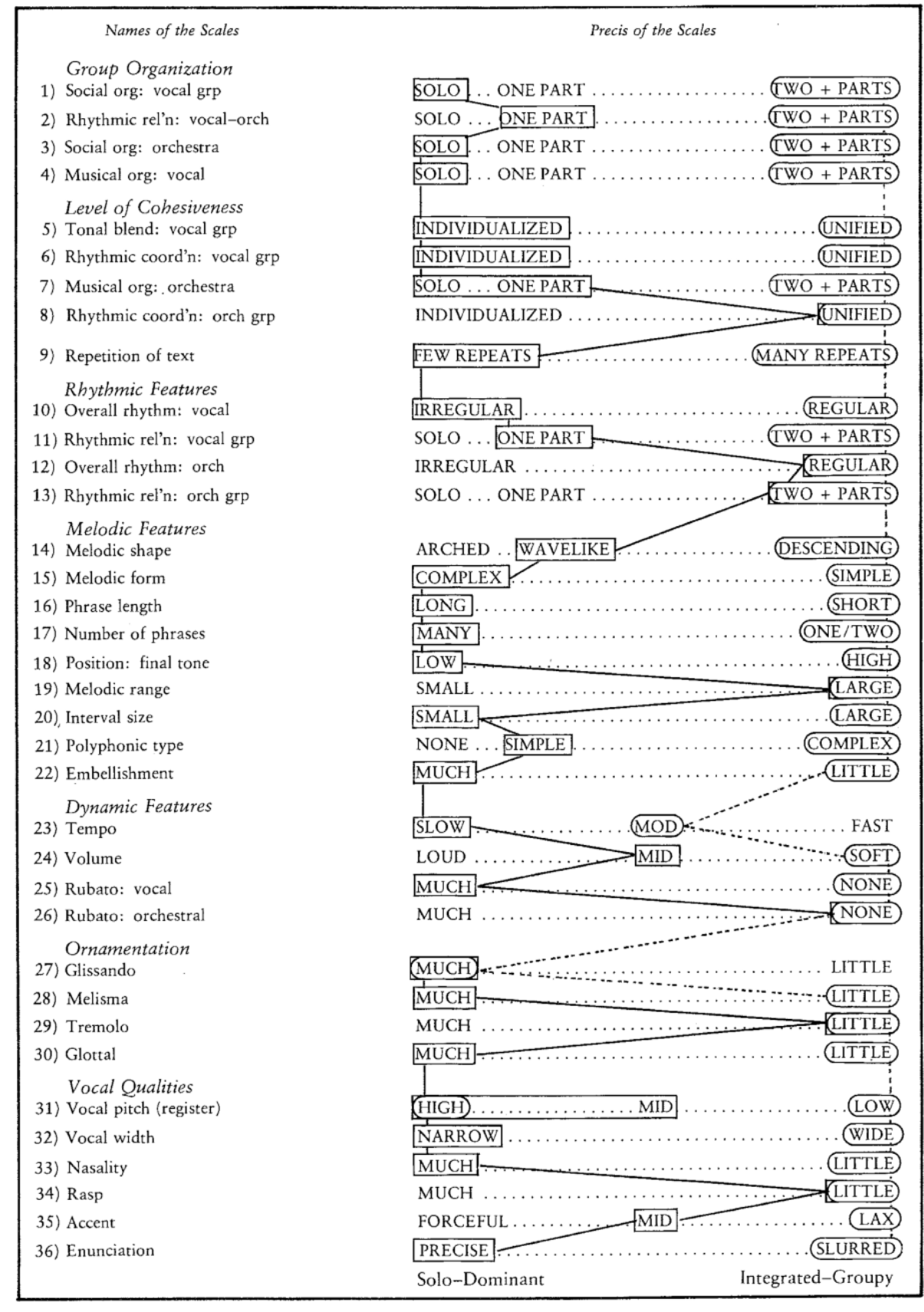

Key: $\begin{aligned} \square & =\text { URBAN EAST ASIA } \\ & =\text { AFRICAN GATHERER }\end{aligned}$

Figure 1. (Cantometrics) Outline of the cantometric scales and their use in contrasting two regional styles: African gatherers and urban East Asia. Courtesy of Alan Lomax.

\section{Figure 2. A sample Cantometric coding sheet (Lomax 1989).}

Ultimately, dispute focused on these correlations led to little acceptance of the Cantometrics Project as a whole for most of the $20^{\text {th }}$ century (Dubinskas 1983; Averill 2003; Wood 2018a, 2018b; Szwed 2010; Savage 2018). However, since Lomax's death in 2002, a few scholars including Lomax's daughter Anna Lomax Wood, Victor Grauer, Armand Leroi, Steven Brown, and myself have tried reviving/refining Lomax's Cantometric approach, focusing not on correlations with social structure but instead on the role of music as a marker of human history (Leroi and Swire 2006; Leroi et al. 2015; Wood 2018a, 2018b; Callaway 2007; 
Grauer 2006; Grauer 2011; Savage et al. 2012; Rzeszutek, Savage, and Brown 2012; Brown et al. 2014; Savage and Brown 2014; Savage, Matsumae, et al. 2015). In 2021, the

Association for Cultural Equity that Lomax founded finally publicly released 5,779

downloadable Cantometric codings along with associated streaming recordings and metadata online at http://www.theglobaljukebox.org (Russonello 2017; Wood et al. 2021). My colleagues and I have also published all of our own Cantometric/CantoCore ${ }^{1}$ codings and related metadata as supplementary material in our own publications that used these systems, totaling over 1,000 songs.

\section{Regional corpora and their limitations}

Recently, there has been increasing awareness of the limitations of focusing on corpora of Western music and the need to build cross-cultural corpora. Many of these corpora have recently been reviewed in detail by Panteli, Benetos, and Dixon (2018), so I will avoid repeating them all here. While I am very supportive of this trend, I also hope it continues to expand from regional corpora to global corpora.

A key issue for many of these studies (including my own) is that their regional focus often means that their results still can not necessarily be generalized beyond the region of focus. Replacing corpus studies of Western music with corpus studies of non-Western music, without cross-cultural comparison between the two, does not solve the problem that music from a single culture or region is not representative of all music. For example, Shanahan, Neubarth, and Conklin (2016) analyzed the Densmore corpus of over 2,083 Native American songs, finding intriguing relationships between song structure and social function (e.g., love songs tend to be high-pitched). However, it remains to be seen whether this relationship is characteristic of music in general as predicted by Huron's (2015) ethological model, or specific to Native American music.

Likewise, my own research has identified significant correlations between musical, genetic, and linguistic diversity among nine indigenous populations of Taiwan (Brown et al. 2014), which we argue suggests that music, like languages and genes, can act as a marker of human population history. However, because we have not yet been able to make this direct comparison for other regions, it remains to be seen whether this relationship holds at a global level (this possibility is bolstered by some suggestive evidence of music-gene correlations from other regional studies; Callaway 2007; Pamjav et al. 2012; Savage, Matsumae, et al. 2015; but cf. Matsumae et al. 2021 for evidence against music-gene correlations in Northeast Asia).

Another interesting case is Xavier Serra's project entitled "Computational models for discovery of the world's music" (CompMusic). At first glance, CompMusic appears to be designed for cross-cultural comparison, through detailed sampling of over 10,000 audio recordings from five regional genres: Hindustani (North India), Carnatic (South India), Turkish makam (Turkey), Arab-Andalusian (Maghreb, or North Africa), and jingju (Beijing Opera; China). However, rather than attempt to develop universal methods for cross-cultural comparison along the lines of the melodic sequence alignment and Cantometrics approaches described above, Serra explicitly chose to focus on developing corpus-specific tools to better

\footnotetext{
${ }^{1}$ CantoCore is a classification scheme we designed that was inspired by Cantometrics but focused on "core" features of song structure such as rhythm, pitch, and texture, rather than the features of performance style emphasized by Cantometrics (Savage et al. 2012).
} 
understand each repertoire on its own terms, without attempting standardized cross-cultural comparisons: "[CompMusic's] major aim has been to advance the automatic analysis of music data by emphasizing cultural specificity" (Serra 2017:24). This type of culture-specific approach remains typical of the emerging field of "computational ethnomusicology", in which MIR researchers develop new technologies to help ethnomusicologists in their traditional domains of the music of individual cultures (Tzanetakis et al. 2007). Culturespecific approaches provide many valuable insights, but do not necessarily advance some of the goals of comparative musicology.

One way of generalizing beyond individual regional corpora is through comparison of two distantly related regional corpora. Such an approach has sometimes been performed using the Essen Folksong database (Schaffrath 1995; Selfridge-Field 1995; cf. Eerola's chapter on folk tune corpora in this volume). This database contains digitized transcriptions of 9,647 folk songs. Of these 9,647 songs, 7,583 are European (mostly German), 2,041 are Chinese, with 23 miscellaneous songs from elsewhere around the world. By comparing the European sample with the Chinese sample, researchers have identified cross-cultural similarities and differences in melodic structure. For example, Huron (1996) initially identified a consistent arch-shape in phrases using the European sample of the Essen folksong database. Tierney, Russo, and Patel (2011) replicated this finding both using the Chinese sample and using a sample of birdsongs, suggesting that this shape is characteristic not only of human music but of vocalizations across species, which they propose is due to motor constraints on vocalization mechanisms (the "motor constraint hypothesis"). On the other hand, Shanahan and Huron (2011) compared interval size distributions between the German and Chinese corpora of the Essen database to provide evidence against motor constraints on melodic structure. Specifically, they argue that the lack of small intervals at the end of Chinese folk songs provides evidence against the general phenomenon of "late phrase compression" found in spoken language (Ladd 2008).

These results from cross-cultural comparison can be more informative about the nature of human music than studies of a corpus from a single style or region. However, it is not clear whether the similarities or differences found between European and Chinese folksongs are characteristic of the world in general. There are many reasons why European and Chinese music might be similar or different. For example, both Europe and China have been part of the flow of music and culture along the Silk Road for millennia, which could have resulted in the diffusion of similar types of phrase shape. On the other hand, Chinese languages are tonal, while European languages are not, and this could potentially account for differences in interval structure (Patel 2008). An analogous point has been made for the study cited above showing indifference to dissonance among the Tsimané. While McDermott et al. (2016:547) use this finding to argue that consonance is "unlikely to reflect innate biases", others have challenged this interpretation, arguing that preference for consonance is a statistical universal that largely reflects innate biases, but that such biases can sometimes be overridden, particularly in cultures such as the Tsimané whose music is primarily monophonic (Bowling et al. 2017; Savage and Currie 2016).

\section{Global corpora}

Understanding similarities and differences in all the world's music necessarily requires a global sample. Cantometrics could provide an ideal sample now that the data have been made publicly available, and several other attempts have been made to develop/utilize global corpora. Our "Deep History of Music Project" aims to apply MIR techniques to a 
combination of over 100,000 recordings from a variety of large global archives including Smithsonian Folkways, the British Library, and the Royal Central African Museum (Leroi et al. 2015). As part of this project, Panteli et al. (2017) have curated a subset of 8,200 songs and published methods and source code for identifying musical outliers within this dataset via automatic feature analysis. However, a major challenge in this work is that the scale of analysis is too large to be done manually by humans as was done with Cantometrics, and MIR technologies are not yet able to match human capabilities when it comes to fine-grained cross-cultural analysis of musical features (Proutskova and Casey 2009; Panteli et al. 2017; Ozaki et al., 2021).

An alternative approach I developed was to focus on manual analysis of a corpus that was much smaller but highly diverse: the Garland Encyclopedia of Music (Nettl et al. 1998-2002). Although primarily a written encyclopedia, Garland includes companion CDs for each of its 9 regional volumes, giving a total of 304 recordings of traditional music from throughout the world (Fig. 3). Because the sampling is sparse and individual songs are not necessarily typical of their entire musical culture, this sample would not be appropriate for an analysis like that attempted by Cantometrics in which the relationship between song and culture is the focus. However, because the sample is so diverse, it provides a useful corpus for testing the presence of universal aspects of music. When we did so by classifying and comparing these recordings using Cantometrics, CantoCore, and the Hornbostel-Sachs instrument classification schemes (Hornbostel and Sachs 1961 [1914]), we found no musical features that were absolute universals found in every example, but dozens of musical features that were statistical universals in that they predominated the repertoires of all 9 regions (Savage, Brown, et al. 2015). In a later study, we applied automatic acoustic analysis to a subset of 35 a cappella vocal songs from the Garland corpus in order to test whether the arched phrase shape described above found by Tierney et al. in the Essen corpus generalized throughout the world's music (Savage, Tierney, and Patel 2017). In addition to confirming that an arched shape did generalize throughout the world, we were surprised to find that our analysis of average phrase contours for songs throughout the globe were actually more similar to average bird song contours than they were to the average human song contours contained in the Essen database (Fig. 4), concluding that "the Essen database is not the most representative sample upon which to base cross-cultural generalizations" (Savage, Tierney, and Patel 2017:332). We have subsequently used automatic analysis of other sub-samples from the Garland corpus to investigate cross-cultural diversity in scale structure, finding that small-integer frequency ratios such as the perfect fifth (3:2 ratio) appear to be statistically universal (Kuroyanagi et al. 2019; Sato et al. 2019). 


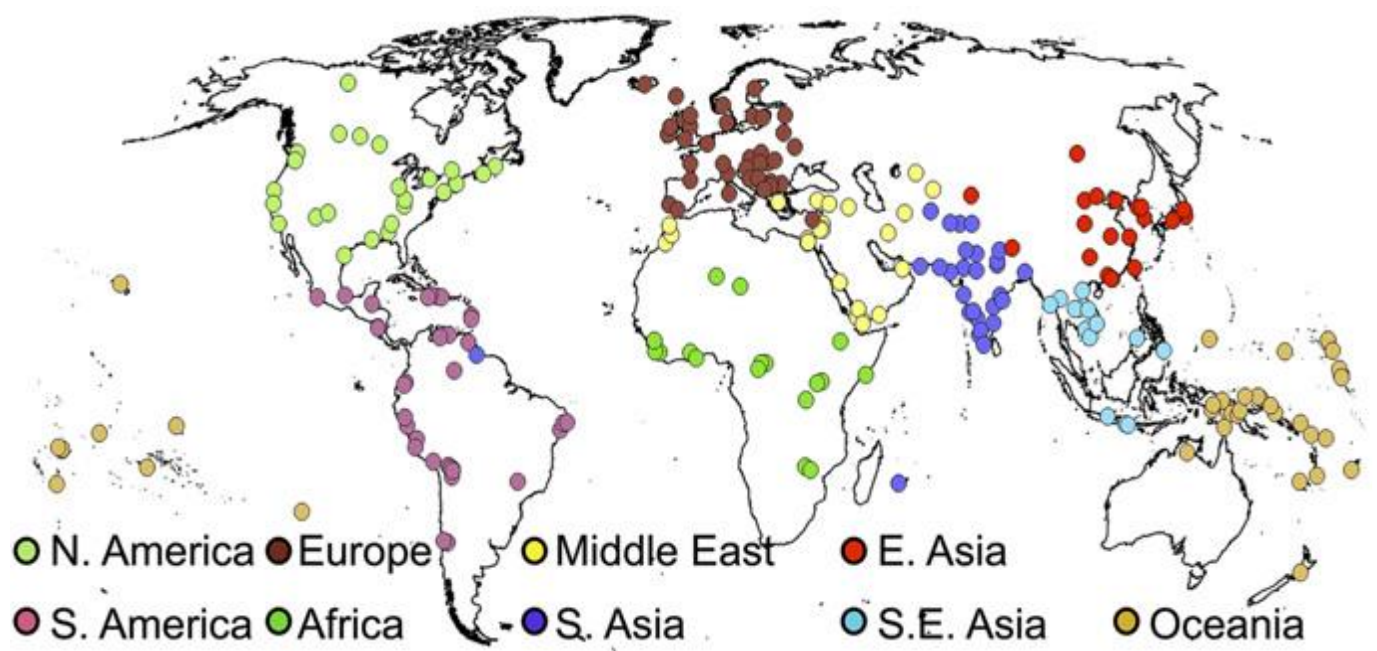

Figure 3. Map of the distribution of the 304 recordings from the Garland corpus (Savage, Brown, et al. 2015)

Figure 4. Comparisons of average phrase contours in Garland, Essen, and bird song corpora (Savage, Tierney, and Patel 2017).

Another project entitled the Natural History of Song (Mehr et al., 2019), has recently adopted a similar approach to investigating universal aspects of music through careful analysis of a small but diverse corpus of 118 traditional songs from around the world. Their corpus provides several important features not present in our Garland corpus: 1) inter-rater reliability data from a large sample of coders ${ }^{2} ; 2$ ) transcriptions for all songs in addition to classifications by ear; 3 ) information about the social function of the songs (sampling was restricted to the categories of love songs, healing songs, dance songs, and lullabies); and 4) information about the broader social context of musical performance, including song lyrics and ethnographic data. Mehr et al. provide some examples of possible ways to address the

${ }^{2}$ Our Garland analysis only provided inter-rater reliability data between myself and Emi Sakai on a random sub-sample of 30 songs (mean agreement $=81 \%$; mean Kappa $=0.45$; (Savage, Brown, et al. 2015)) 
challenges of combining audio, symbolic notation, and written text using both automatic and manual analysis. For example, some of their analyses use machine learning to combine features automatically extracted from the audio files with manual features transcribed or classified by human listeners. Their heavy reliance on transcription using Western staff notation and claims of universal associations between song structure and social function have generated substantial controversy (Marshall 2018; Yong 2018; Rasmussen \& Cowdry 2018; Woo 2019).

\section{Conclusions}

It is clear that the advent of "big data" and an awareness of the pitfalls of "WEIRD" samples reliant on Western music is transforming musicology. However, there still remains a surprising lack of cross-cultural musical corpus studies, especially on a global scale. This is partly due to challenges in designing methods that are appropriate for analyzing musical notation and musical recordings cross-culturally, especially in ways that can be performed automatically through computational analysis of large samples.

We have seen how the choice of methods and corpora used can depend on the research goals. For example, culture-specific corpora can be appropriate for project such as CompMusic that aim to develop technologies that can be used by members of a given music culture, while global corpora may be more useful for studies aimed at identifying universal aspects of human music. Likewise, automated analysis may be preferable when the scale of analysis is too large or requires levels of detail too fine-grained to be feasible for humans, while some high-level tasks that are achievable by humans remain (for now) too challenging for accurate cross-cultural automated analysis (e.g., polyphonic transcription; Benetos et al. 2019).

In addition to the challenges outlined in the case studies presented, another challenge that has still been under-explored is applying cross-cultural corpus studies beyond academia. The results of these corpus studies should be relevant to the music industry (e.g., Apple, Pandora, Yamaha; cf. Daikoku et al. 2020) and to cultural heritage organizations that are responsible for preserving and promoting the world's cultural diversity (e.g., UNESCO). Although there is already substantial collaboration between the music industry and the MIR community and between cultural heritage organizations and the ethnomusicological community, crosscultural corpus studies have yet to make a substantial impact in either area. The development and utilization of bigger and better global music corpora may help give corpus studies more impact and lead to a stronger relationship between music corpus studies and other relevant communities, both inside and outside academia.

\section{References}

Averill, Gage. 2003. "Cantometrics and Cultural Equity: The Academic Years." In Alan Lomax: Selected Writings, 1934-1997, edited by Ronald D. Cohen, 233-48. New York: Routledge.

Bayard, Samuel P. 1950. "Prolegomena to a Study of the Principal Melodic Families of British-American Folk Song." Journal of American Folklore 63 (247): 1-44.

Benetos, Emmanouil, Simon Dixon, Zhiyao Duan, and Sebastian Ewert. 2019. "Automatic Music Transcription: An Overview.” IEEE Signal Processing Magazine 36 (1): 20-30. https://doi.org/10.1109/MSP.2018.2869928

Bertin-Mahieux, Thierry, Daniel P.W. Ellis, Brian Whitman, and Paul Lamere. 2011. "The Million Song Dataset." Proceedings of the 12th International Society for Music Information Retrieval Conference (ISMIR 2011), 591-96. 
Bowling, Daniel L., Marisa Hoeschele, Kamraan Z. Gill, and W. Tecumseh Fitch. 2017. "The Nature and Nurture of Musical Consonance." Music Perception 35 (1): 118-21.

Bronson, Bertrand H. 1949. "Mechanical Help in the Study of Folk Song." Journal of American Folklore 62 (244): 81-86.

1959-72. The Traditional Tunes of the Child Ballads: With Their Texts, according to the Extant Records of Great Britain and America [4 Volumes]. Princeton, NJ: Princeton University Press.

. 1969. The Ballad as Song. Berkeley: University of California Press.

Brown, Steven, and Joseph Jordania. 2013. "Universals in the World's Musics." Psychology of Music 41 (2): 229-48.

Brown, Steven, Patrick E. Savage, Albert Min-Shan Ko, Mark Stoneking, Ying-Chin Ko, Jun-Hun Loo, and Jean A. Trejaut. 2014. "Correlations in the Population Structure of Music, Genes and Language." Proceedings of the Royal Society B: Biological Sciences 281 (1774): 20132072.

Callaway, Ewen. 2007. "Music Is in Our Genes." Nature News. doi:10.1038/news.2007.359.

Daikoku, Hideo, Anna L. C. Wood, and Patrick E. Savage. 2020. "Musical Diversity in India: A Preliminary Computational Study Using Cantometrics." Keio SFC Journal 20 (2): 34-61. https://gakkai.sfc.keio.ac.jp/journal/.assets/SFCJ20-2-03.pdf

Dubinskas, Frank A. 1983. "A Musical Joseph's Coat: Patchwork Patterns and Social Significance in World Musics." Reviews in Anthropology 10 (3): 27-42.

Eerola, Tuomas. In press. "Folksong Corpora." In Oxford Handbook of Music and Corpus Studies, edited by Daniel Shanahan, Ashley Burgoyne, and Ian Quinn. New York: Oxford University Press.

Ellis, Alexander J. 1885. "On the Musical Scales of Various Nations." Journal of the Society of Arts 33 (1): 485-527.

Geertz, Clifford. 1973. The Interpretation of Cultures. New York: Basic Books.

Grauer, Victor A. 2006. "Echoes of Our Forgotten Ancestors." The World of Music 48 (2): 558.

- 2011. Sounding the Depths: Tradition and the Voices of History. CreateSpace: http://soundingthedepths.blogspot.com/.

Henrich, Joseph, Steven J. Heine, and Ara Norenzayan. 2010. "The Weirdest People in the World?" The Behavioral and Brain Sciences 33: 61-135.

Hornbostel, Erich M. von. 1975. Hornbostel Opera Omnia. Edited by Klaus P. Wachmann, Dieter Christensen, and Hans-Pieter Reinecke. The Hague: Marinus Nijhoff.

Hornbostel, Erich M. von, and Curt Sachs. 1961 [1914]. "Classification of Musical Instruments." Translated by Anthony Baines and Klaus P. Wachmann. Galpin Society Journal 14 (Mar): 3-29.

Huron, David. 1996. "The Melodic Arch in Western Folksongs." Computing in Musicology 10: 3-23.

—. 2008. "Lost in Music." Nature 453 (May): 456-57.

- 2015. "Affect Induction through Musical Sounds: An Ethological Perspective." Philosophical Transactions of the Royal Society B: Biological Sciences 370 (1664): 20140098. doi:10.1098/rstb.2014.0098.

Jacoby, Nori, Elizabeth H. Margulis, Martin Clayton, Erin Hannon, Henkjan Honing, John Iversen, Tobias Robert Klein, et al. 2020. "Cross-Cultural Work in Music Cognition: Methodologies, Pitfalls, and Practices.” Music Perception 37 (3): 185-95. https://doi.org/10.1525/mp.2020.37.3.185

Kuroyanagi, Jiei, Shoichiro Sato, Meng-Jou Ho, Gakuto Chiba, Joren Six, Peter Pfordresher, Adam Tierney, Shinya Fujii, and Patrick E. Savage. 2019. "Automatic Comparison of Human Music, Speech, and Bird Song Suggests Uniqueness of Human Scales.” In 
Proceedings of the 9th International Workshop on Folk Music Analysis (FMA2019), 35-

40. https://doi.org/10.31234/osf.io/zpv5w

Ladd, D.R. 2008. Intonational Phonology. 2nd ed. Cambridge: Cambridge University Press. Leroi, Armand M., Matthias Mauch, Patrick E. Savage, Emmanouil Benetos, Juan Bello, Maria Panteli, Joren Six, and Tillman Weyde. 2015. "The Deep History of Music Project." In Proceedings of the Folk Music Analysis 2015 Workshop, 83-84.

Leroi, Armand M., and Jonathan Swire. 2006. "The Recovery of the Past." The World of Music 48 (3): 43-54.

Lomax, Alan, ed. 1968. Folk Song Style and Culture. Washington, DC: American

Association for the Advancement of Science. - 1976. Cantometrics: An Approach to the Anthropology of Music. Berkeley:

University of California Extension Media Center.

- 1980. "Factors of Musical Style." In Theory \& Practice: Essays Presented to Gene Weltfish, edited by Stanley Diamond, 29-58. The Hague: Mouton.

- 1989. "Cantometrics." International Encyclopedia of Communications. New York: Oxford University Press.

Marshall, Alex. 2018. "Can You Tell a Lullaby from a Love Song? Find out Now." New York Times, January 25. https://www.nytimes.com/interactive/2018/01/25/arts/music/historyof-song.html

Matsumae, Hiromi, Peter Ranacher, Patrick E. Savage, Damián E. Blasi, Thomas E. Currie, Kae Koganebuchi, Nao Nishida, et al. 2021. "Exploring Correlations in Genetic and Cultural Variation across Language Families in Northeast Asia." Science Advances. https://doi.org/10.1126/sciadv.abd9223

McDermott, Josh H., Alan F. Schultz, Eduardo A. Undurraga, and Ricardo A. Godoy. 2016. "Indifference to Dissonance in Native Amazonians Reveals Cultural Variation in Music Perception." Nature 535: 547-550.

Mehr, Samuel A., Manvir Singh, Hunter York, Luke Glowacki, and Max M. Krasnow. 2018. "Form and Function in Human Song." Current Biology 28: 356-68.

Mehr, Samuel A., Manvir Singh, Dean Knox, Daniel M. Ketter, Daniel Pickens-Jones, Stephanie Atwood, Christopher Lucas, et al. 2019. "Universality and Diversity in Human Song." Science 366: eaax0868. https://doi.org/10.1126/science.aax0868

Murdock, George P. 1967. “Ethnographic Atlas: A Summary.” Ethnology 6 (2): 109-236.

Nettl, Bruno. 2015. The Study of Ethnomusicology: Thirty-Three Discussions. 3rd ed. Champaign: University of Illinois Press.

Nettl, Bruno, and Philip V. Bohlman, eds. 1991. Comparative Musicology and Anthropology of Music: Essays on the History of Ethnomusicology. Chicago: University of Chicago Press.

Nettl, Bruno, Ruth Stone, James Porter, and Timothy Rice, eds. 1998-2002. The Garland Encyclopedia of World Music [10 Volumes; 9 CDs]. New York: Garland Pub.

NHK (Nippon Hōsō Kyōkai), ed. 1944-94. Nihon Min'yō Taikan [Japanese Folk Song Anthology] [13 Volumes]. Tokyo: NHK.

Ozaki, Yuto, John McBride, Emmanouil Benetos, Peter Pfordresher, Joren Six, Adam T. Tierney, Polina Proutskova, et al. 2021. "Agreement among Human and Automated Transcriptions of Global Songs.” https://openreview.net/forum?id=WL_MC7HgGQ

Pamjav, Horolma, Zoltán Juhász, Andrea Zalán, Endre Németh, and Bayarlkhagva Damdin. 2012. "A Comparative Phylogenetic Study of Genetics and Folk Music.” Molecular Genetics and Genomics 287 (4): 337-49.

Panteli, Maria, Emmanouil Benetos, and Simon Dixon. 2018. "A Review of Manual and Computational Approaches for the Study of World Music Corpora." Journal of New Music Research 47 (2): 176-89. 
2017. "A Computational Study on Outliers in World Music." PLOS ONE 12 (12): e0189399. doi:10.1371/journal.pone.0189399.

Patel, Aniruddh D. 2008. Music, Language and the Brain. Oxford: Oxford University Press.

Proutskova, Polina, and Michael Casey. 2009. "You Call That Singing? Ensemble Classification for Multi-Cultural Collections of Music Recordings." In ISMIR Proceedings, 759-64.

Rasmussen, Anne, and Jim Cowdery. 2018. "Forum: The Lure of Universals." Society for Ethnomusicology Newsletter 52 (2): 7-8.

https://cdn.ymaws.com/www.ethnomusicology.org/resource/resmgr/newsletters/SEMN $\underline{\text { L52-2.pdf }}$

Russonello, Giovanni. 2017. "The Unfinished Work of Alan Lomax's Global Jukebox." New York Times, July 11. https://www.nytimes.com/2017/07/11/arts/music/alan-lomaxglobal-jukebox-digital-archive.html.

Rzeszutek, Tom, Patrick E. Savage, and Steven Brown. 2012. "The Structure of CrossCultural Musical Diversity." Proceedings of the Royal Society B: Biological Sciences 279 (1733): 1606-12.

Sachs, Curt. 1962. The Wellsprings of Music. Edited by Jaap Kunst. The Hague: M. Nijhoff. Sato, Shoichiro, Joren Six, Peter Pfordresher, Shinya Fujii, and Patrick E. Savage. 2019.

"Automatic Comparison of Global Children's and Adult Songs Supports a Sensorimotor Hypothesis for the Origin of Musical Scales." In Proceedings of the 9th International Workshop on Folk Music Analysis (FMA2019), 41-46. https://doi.org/10.31234/osf.io/kt7py

Savage, Patrick E. 2018. "Alan Lomax's Cantometrics Project: A Comprehensive Review." Music \& Science 1: 1-19. http://doi.org/10.1177/2059204318786084.

- Under contract. Comparative Musicology: The Science of the World's Music. Oxford University Press.

- 2019. "Cultural Evolution of Music." Palgrave Communications 5 (16): 1-12. https://doi.org/10.1057/s41599-019-0221-1.

—. 2017. “音楽の文化的進化を測る——ブリティッシュ・アメリカンと日本の

民謡・ポップス・古典音楽の事例を通して—— [Measuring the Cultural Evolution of Music: With Case Studies of British-American and Japanese Folk, Art, and Popular Music]." Ph.D. diss., Tokyo University of the Arts.

Savage, Patrick E., and Quentin D. Atkinson. 2015. "Automatic Tune Family Identification by Musical Sequence Alignment." In Proceedings of the 16th International Society for Music Information Retrieval Conference (ISMIR 2015), 162-68.

Savage, Patrick E., and Steven Brown. 2013. "Toward a New Comparative Musicology." Analytical Approaches to World Music 2 (2): 148-197.

- 2014. "Mapping Music: Cluster Analysis of Song-Type Frequencies within and between Cultures." Ethnomusicology 58 (1): 133-55.

Savage, Patrick E., Steven Brown, Emi Sakai, and Thomas E. Currie. 2015. "Statistical Universals Reveal the Structures and Functions of Human Music." Proceedings of the National Academy of Sciences of the United States of America 112 (29): 8987-92.

Savage, Patrick E., Charles Cronin, Daniel Müllensiefen, and Quentin D. Atkinson. 2018. "Quantitative Evaluation of Music Copyright Infringement." In Proceedings of the Folk Music Analysis 2018 Workshop, 61-66.

http://fma2018.mus.auth.gr/files/papers/FMA2018_paper_4.pdf

Savage, Patrick E., and Thomas E. Currie. 2016. "Music Perception: No Strong Evidence to Reject Innate Biases.” SocArXiv preprint. https://doi.org/10.17605/OSF.IO/964UT

Savage, Patrick E., Gakuto Chiba, Thomas E. Currie, Haruo Suzuki, Sam Passmore, and 
Quentin D. Atkinson. 2020. "Sequence Alignment of Folk Song Melodies Reveals Cross-Cultural Mechanisms of Musical Evolution." PsyArXiv preprint.

https://doi.org/10.31234/osf.io/5rj6y

Savage, Patrick E., Hiromi Matsumae, Hiroki Oota, Mark Stoneking, Thomas E. Currie, Atsushi Tajima, Matt Gillan, and Steven Brown. 2015. "How 'Circumpolar' Is Ainu Music? Musical and Genetic Perspectives on the History of the Japanese Archipelago." Ethnomusicology Forum 24 (3): 443-467.

Savage, Patrick E., Emily Merritt, Tom Rzeszutek, and Steven Brown. 2012. "CantoCore: A New Cross-Cultural Song Classification Scheme.” Analytical Approaches to World Music 2 (1): 87-137.

Savage, Patrick E., Adam T. Tierney, and Aniruddh D. Patel. 2017. "Global Music Recordings Support the Motor Constraint Hypothesis for Human and Avian Song Contour." Music Perception 34 (3): 327-34.

Schaffrath, Helmut. 1995. The Essen Folksong Database in Kern Format. Edited by David Huron. Menlo Park, CA: Center for Computer Assisted Research in the Humanities.

Schneider, Albrecht, ed. 2008. Systematic and Comparative Musicology: Concepts, Methods, Findings. Frankfurt: Peter Lang.

Selfridge-Field, E. 1995. The Essen Musical Data Package. Menlo Park, CA: Center for Computer Assisted Research in the Humanities (CCARH).

Serra, Xavier. 2011. "A Multicultural Approach in Music Information Research.” In

Proceedings of the 12th International Society for Music Information Retrieval

Conference (ISMIR 2011), 151-56.

- 2017. "The Computational Study of a Musical Culture through Its Digital Traces." Acta Musicologica 89 (1): 24-44.

Shanahan, Daniel, and David Huron. 2011. "Interval Size and Phrase Position: A Comparison between German and Chinese Folksongs." Empirical Musicology Review 6 (4): 187-97.

Shanahan, Daniel, Kerstin Neubarth, and Darrell Conklin. 2016. "Mining Musical Traits of Social Functions in Native American Music.” In 17th International Society for Music Information Retrieval Conference (ISMIR 2016), 681-87.

Stumpf, Carl. 2012 [1911]. The Origins of Music. Translated by David Trippett. Oxford: Oxford University Press.

Szwed, John. 2010. Alan Lomax: The Man Who Recorded the World. New York: Viking.

Temperley, David, and Leigh VanHandel. 2013. "Introduction to the Special Issues on Corpus Methods." Music Perception 31 (1): 1-3.

Tierney, Adam T., Frank A. Russo, and Aniruddh D. Patel. 2011. "The Motor Origins of Human and Avian Song Structure." Proceedings of the National Academy of Sciences of the United States of America 108 (37): 15510-15515.

Toner, P.G. 2007. "The Gestation of Cross-Cultural Music Research and the Birth of Ethnomusicology." Humanities Research 14 (1): 85-110.

Tzanetakis, George, Ajay Kapur, W. Andrew Schloss, and Matthew Wright. 2007. "Computational Ethnomusicology." Journal of Interdisciplinary Music Studies 1 (2): 124.

VanHandel, Leigh, and David Temperley. 2014. "Introduction to the Second Special Issue on Corpus Methods." Music Perception 31 (3): 191.

Wiedmann, Albrecht, Ricarda Kopal, and Ulrich Wegner, eds. 2011. Music! The Berlin Phonogramm-Archiv 1900-2011 in 111 Recordings [5CDs + 312-p Booklet]. Reihe: Museum Collection Berlin 27.

Woo, Marcus. 2019. "Music May Really Be a Universal Language." Inside Science, November 21, 2019. https://www.insidescience.org/news/music-may-really-beuniversal-language 
Wood, Anna L. C. 2018a. "'Like a Cry from the Heart': An Insider's View on the Genesis of Alan Lomax's Ideas and the Legacy of His Research: Part I." Ethnomusicology 62 (2): 230-64.

. 2018b. "Like a Cry from the Heart': An Insider's View on the Genesis of Alan Lomax's Ideas and the Legacy of His Research: Part II.” Ethnomusicology 62 (3): 40338.

Wood, Anna L. C., Kathryn R. Kirby, Carol R. Ember, Stella Silbert, Hideo Daikoku, John McBride, Sam Passmore, et al. 2021. "The Global Jukebox: A Public Database of Performing Arts and Culture.” PsyArXiv preprint. https://doi.org/10.31234/osf.io/4z97j

Yong, Ed. 2018. "A Study Suggests That People Can Hear Universal Traits in Music: But Some Music Scholars Have Doubts.” The Atlantic, January 25, 2018.

https://www.theatlantic.com/science/archive/2018/01/the-search-for-universal-qualitiesin-music-heats-up/551447

Ziegler, Susanne. 2006. Die Wachszylinder Des Berliner Phonogramm-Archivs. Berlin: Ethnologisches Museum, Staatliche Museen zu Berlin.

Ziegler, Susanne. 2017. "Institutional Histories Entry : The Berlin Phonogramm - Archiv," no. 1: 1-2. http://www.ethnomusicology.org/?HS_InsBerlin\#. 